\title{
Editorial
}

\section{Advanced Nanomaterials and Nanotechnologies for Solar Energy}

\author{
Wei Wei $\mathbb{D}^{1}{ }^{1}$ Hui Wang, ${ }^{2}$ Chunling Wang, ${ }^{3}$ and Hongmei Luo ${ }^{4}$ \\ ${ }^{1}$ Mechanical Engineering Department, Wichita State University, Wichita, KS 67260, USA \\ ${ }^{2}$ Mechanical Engineering Department, University of Louisville, Louisville, KY 40222, USA \\ ${ }^{3}$ School of Environmental Science and Engineering, Shanghai Jiao Tong University, Shanghai 200240, China \\ ${ }^{4}$ Chemical \& Materials Engineering Department, New Mexico State University, Las Cruces, New Mexico 88003, USA \\ Correspondence should be addressed to Wei Wei; wei.wei@wichita.edu
}

Received 29 May 2019; Accepted 3 June 2019; Published 24 July 2019

Copyright (@) 2019 Wei Wei et al. This is an open access article distributed under the Creative Commons Attribution License, which permits unrestricted use, distribution, and reproduction in any medium, provided the original work is properly cited.

As the world faces serious energy challenges, the development and implementation of renewable energy technologies become increasingly important. Solar energy resource dwarfs all other renewable and fossil-based energy resources combined. This special issue addresses the role of the development of solar energy. The themes include a photocatalytic process, a photoelectrochemical process, a photosynthesis process, solar cell technologies (photovoltaics (PV)), and solar PV/thermal systems, which resulted in a collection of twelve outstanding articles submitted by investigators representing eleven countries across Asia, Europe, and North America.

Solar energy can be converted into chemical energy via photocatalytic processes, photoelectrochemical processes, and photosynthesis processes. E. Kao et al. ("Atomic Layer Deposition of $\mathrm{TiO}_{2}$ Nanocoatings on $\mathrm{ZnO}$ Nanowires for Improved Photocatalytic Stability") employed a hybrid hydrothermal/atomic layer deposition method to prepare the high-aspect ratio and vertically ordered $\mathrm{ZnO} / \mathrm{TiO}_{2}$ nanoarrays. The $\mathrm{ZnO} / \mathrm{TiO}_{2}$ nanoarrays were further investigated for applications in solar-powered hydrogen gas harvesters, which showed improved stability and excellent onset voltage. A hydrothermal method was also employed by Y. Niu et al. to synthesize CoS-loaded $\mathrm{TiO}_{2}$ photocatalysts for hydrogen and methanol production. It was demonstrated that $\mathrm{CoS}$ can act as an effective cocatalyst due to the efficient charge separation. C. C. Mercado et al. ("Comparison of Photoelectrochemical Current in Amorphous and Crystalline Anodized $\mathrm{TiO}_{2}$ Nanotube Electrodes") investigated the effect of anodization at low temperature on the properties and photoelectrochemical performance of $\mathrm{TiO}_{2}$. The anodized $\mathrm{TiO}_{2}$ showed determined cathodic photoelectrochemical response, which proved that it could be potential materials for photocatalytic applications. E. Morais et al. ("Visible Light-Driven Gas-Phase Artificial Photosynthesis Reactions over Ruthenium Metal Nanoparticles Modified with Anatase $\mathrm{TiO}_{2}$ ") synthesized narrow size distributed Ruthenium metal nanoparticles via a facile one-pot solvothermal method. The obtained photocatalyst was further tested in the $\mathrm{CO}_{2}+\mathrm{H}_{2} \mathrm{O}$ reaction to produce $\mathrm{CH}_{4}$ and $\mathrm{CO}$. The light absorption properties, the photocatalytic activity, and $\mathrm{CH}_{4} / \mathrm{CO}$ selectivity of the catalyst were modified by incorporating Ti-containing precursors.

Photosynthesis is another process that takes advantage of sunlight. J. F. Monzon-Bensojo et al. ("Photosynthetic Pigments with Potential for a Photosynthetic Antenna: A DFT Analysis") employed chemical reactivity density functional theory (CRDFT) and time-dependent DFT (TD-DFT) methods to evaluate the electronic properties of photosynthetic pigments at the gas phase. This work constitutes a suitable option to study geometrical and molecular properties of natural dyes.

Solar cell technologies have been showing great potential in converting solar energy into electricity. N. A. Martynova et al. ("Electrochemical Coprecipitation of Zinc and Aluminum in Aqueous Electrolytes for $\mathrm{ZnO}$ and AZO Coverage Deposition") employed zinc oxide and Al-doped $\mathrm{ZnO}$ films, which were synthesized via an electrochemical method, as transparent conductive oxide coating for solar cell. V. Loryuenyong et al. ("The Synthesis of $2 \mathrm{D} \mathrm{CH}_{3} \mathrm{NH}_{3} \mathrm{PbI}_{3}$ 
Perovskite Films with Tunable Bandgaps by Solution Deposition Route") investigated the bandgap tuning of hybrid mixed-halide perovskite films. The films were prepared by a sequential two-step deposition technique, which showed higher moisture resistance, better surface coverage, and smaller grain size. D. H. Phuc et al. ("Band Tunable CdSe Quantum Dot-Doped Metals for Quantum Dot-Sensitized Solar Cell Application") prepared the quantum dot solar cells with an efficiency of $4.3 \%$ based on CdSe:X $\left(\mathrm{Mn}^{2+}\right.$ or $\left.\mathrm{Cu}^{2+}\right)$ nanocrystal. A. Uzum et al. (" $\mathrm{H}_{2} \mathrm{O} / \mathrm{O}_{2}$ Vapor Annealing Effect on Spin Coating Alumina Thin Films for Passivation of Silicon Solar Cells") prepared aluminum acetylacetonatebased $\mathrm{AlO}_{\mathrm{x}}$ thin films as low-cost, high-quality passivation layers for crystalline silicon solar cells. D. N. Liyanage et al. ("Donor- $\pi$-Conjugated Spacer-Acceptor Dye-Sensitized Solid-State Solar Cell Using CuI as the Hole Collector") fabricated a solid-state solar cell using copper iodide (CuI) as the hole conductor and alkyl-functionalized carbazole dye as the sensitizer with a power conversion efficiency of $3.33 \%$. In K. Patil et al.'s ("Recent Progress of Graphene-Based Photoelectrode Materials for Dye-Sensitized Solar Cells") review paper, they outlined the strategies to enhance the efficiency and reduce the cost by introducing graphene into the dyesensitized solar cells as the photoelectrode.

A. Ahmed et al. (Use of Nanofluids in Solar PV/Thermal Systems) presented the recent studies in the application of nanofluids in photovoltaic thermal, concentrated photovoltaic thermal, and other solar systems. The important parameters that can improve the performance of nanofluids were also highlighted.

These papers represent an exciting, insightful observation into the state-of-the-art as well as emerging future topics in this important interdisciplinary field. We hope that this special issue would attract a major attention of the peers.

\section{Conflicts of Interest}

There are no conflicts to declare.

\section{Acknowledgments}

The authors would like to express their appreciation to all the authors and reviewers.

Wei Wei

Hui Wang

Chunling Wang

Hongmei Luo 

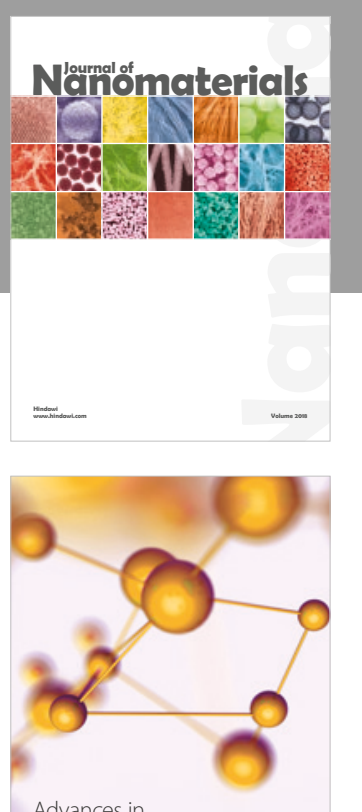

Physical Chemistry
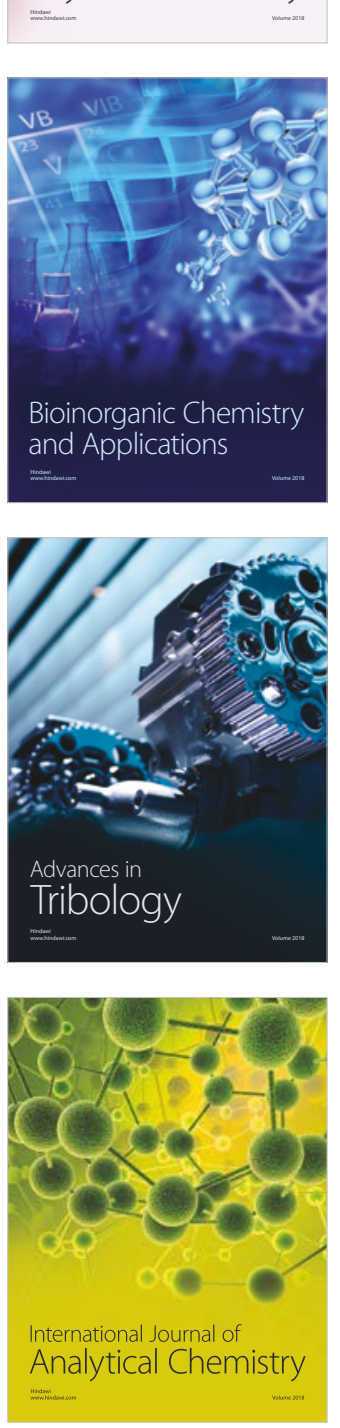

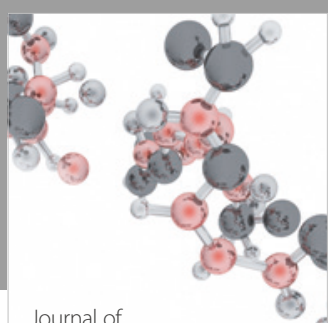

Analytical Methods

in Chemistry

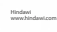

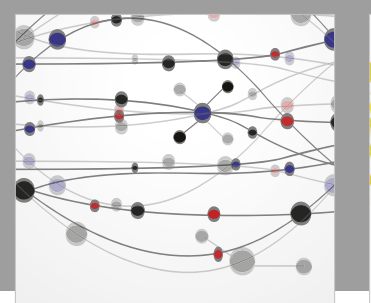

The Scientific World Journal

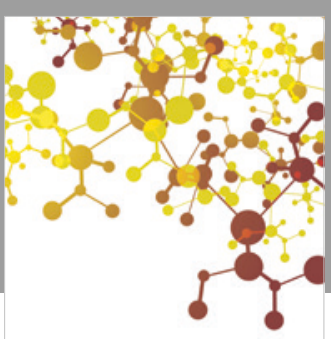

Journal of

Applied Chemistry
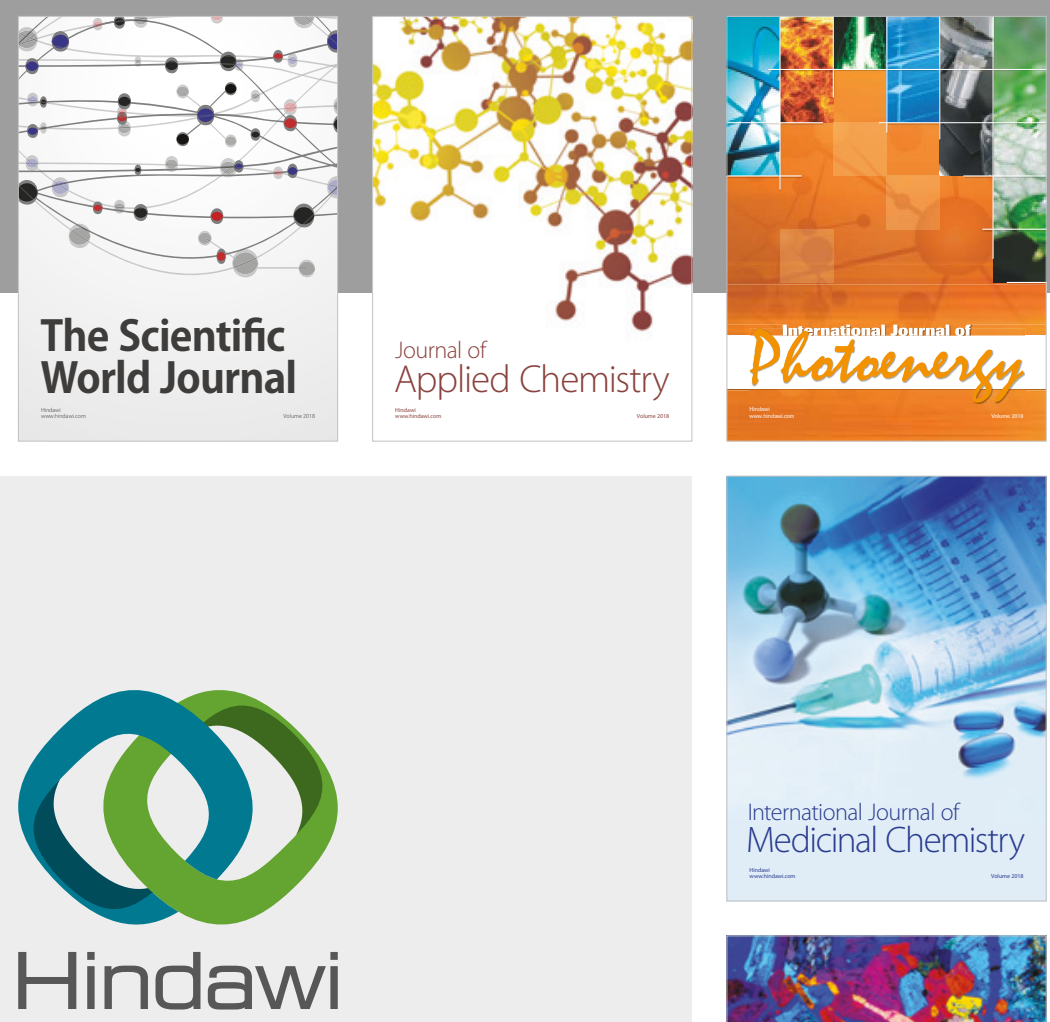

Submit your manuscripts at

www.hindawi.com
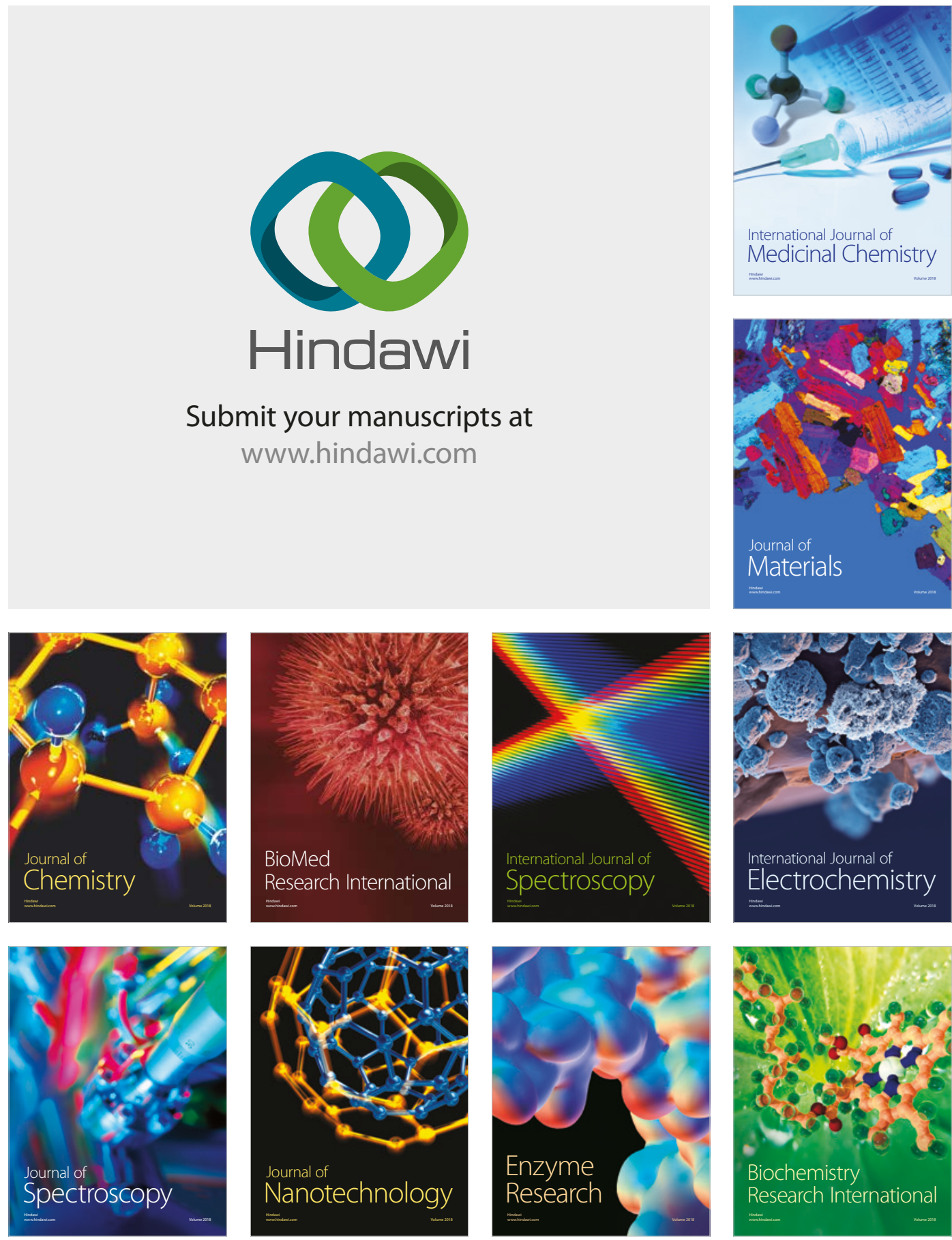
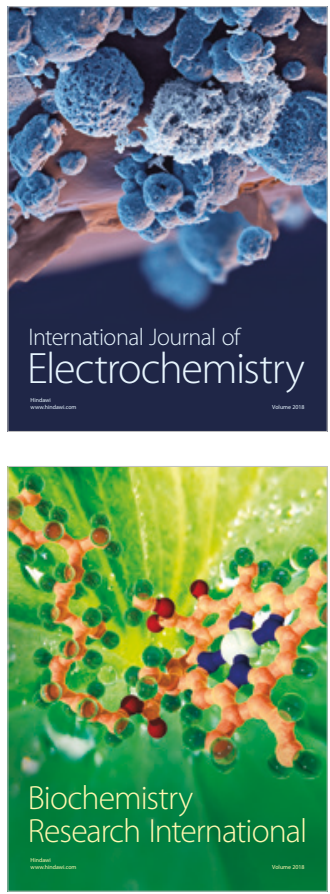